J. Clin. Chem. Clin. Biochem.

Vol. 26, 1988, pp. 85-90

(C) 1988 Walter de Gruyter \& Co. Berlin - New York

\title{
An Alternative Approach to the Prevention of Succinyldicholine-Induced Apnoea $\left.{ }^{1}\right)$
}

\author{
By M. Panteghini, R. Bonora and F. Pagani \\ $1^{\circ}$ Laboratorio Analisi Chimico-Cliniche, Spedali Civili, Brescia, Italy
}

(Received October 19, 1987)

Summary: Succinyldithiocholine was utilized as a substrate analogue of succinyldicholine to study normal and atypical serum pseudocholinesterase (EC 3.1.1.8). In the method, the enzyme acts on succinyldithiocholine to release thiocholine, which reacts with 5,5'-dithio-bis-(2-nitrobenzoic acid) to produce a coloured compound with maximal absorbance at $410 \mathrm{~nm}$. The procedure appears to be precise (between-day analysis gives a coefficient of variation between 1.1 and $3.7 \%$ ) and amenable to automation, permitting routine use in any laboratory. The reference interval for 300 healthy adults with "usual" cholinesterase genotype was estimated to be $34-77 \mathrm{U} / 1$, with a significant difference between males and females (40-78 U/1 for men and 33-76 U/1 for women, $\mathrm{p}<0.01$ ). The median activity in 105 individuals with "heterozygous" cholinesterase genotype was $22 \mathrm{U} / 1$ (range $5-35 \mathrm{U} / \mathrm{l}$ ), and for 14 "atypical" homozygotes $1.5 \mathrm{U} / 1$ (range $1-4 \mathrm{U} / \mathrm{l}$ ). The assay with succinyldithiocholine may offer a direct procedure for preoperative screening of individuals with an abnormal response to the muscle relaxant succinyldicholine, thus avoiding the determination of genotype by measurement of inhibitor numbers.

\section{Introduction}

The determination of human serum pseudocholinesterase (acylcholine acylhydrolase, EC 3.1.1.8) catalytic activity is frequently requested for the detection of patients with atypical forms of the enzyme which reacts abnormally with succinyldicholine (suxamethonium), employed as a neuromuscular blocking agent (1). This is a qualitative variation of the enzyme activity which finds its analytical expression in differences of substrate specificity and susceptibility to inhibition (2-4), and its clinical expression in prolonged apnoea in the patients during anaesthesia, resulting from failure of the atypical enzyme to hydrolyse suxamethonium (5).

Usually, for biochemical identification of succinyldicholine-sensitive individuals, the standard reaction is run with and without the inhibitors, notably dibucaine (2) and fluoride (6). But the kinetic behaviour of

1) Presented in part at the 13th International Congress of Clinical Chemistry, The Hague, The Netherlands, July 1987. normal and atypical cholinesterases could, in part, be a function of the substrate and/or inhibitor employed (7). Furthermore, some patients who would not be expected to possess a gross abnormality of succinyldicholine hydrolysis on the basis of inhibitory criteria in vitro can be quite clearly shown to be sensitive on exposure to this agent in vivo (1). A direct assay, suitable for routine analyses, without the use of inhibitors is therefore desirable.

The purpose of the present paper is to describe a preoperative screening procedure, adaptable to automatic analysers, for the direct detection of human sera with atypical succinyldicholine sensitivity. Succinyldithiocholine is used as the substrate, as proposed by Hersh et al. (8). This compound is an analogue of the natural substrate succinyldicholine (9), from which it differs much less than other substrates frequently used, i.e. acetylthiocholine (10), butyrylthiocholine (11), propionylthiocholine (12), benzoylcholine (13), and p-hydroxybenzoylcholine (14). In particular, the substitution of sulfur for oxygen results 
in no significant change in the kinetic properties of the enzyme (15). The principle of the method is the measurement of the rate of production of thiocholine when succinyldithiocholine is hydrolysed. This is accomplished by the procedure of Ellman in which the thiocholine produced by enzymic hydrolysis is measured by reaction with 5,5'-dithio-bis-(2-nitrobenzoic acid) (15). The assay was compared with a benzoylcholine system (13) directly derived from the classic method of Kalow \& Genest (2), which is considered to be the best available for distinguishing between succinyldicholine-sensitive and nonsensitive patients (11).

\section{Materials and Methods}

\section{Blood samples}

Sera containing the homozygous "atypical" (AA) enzyme used for this study were obtained from hospital patients who experienced prolonged apnoea (20 min or more) when treated with succinyldicholine in conjunction with surgery. "Heterozygous" (UA) enzymes were, obtained from the preoperative routine cholinesterase analysis of all surgical cases in our hospital. Specimens of serum were also obtained from hospitalized patients with terminal stage hepatic cirrhosis and associated "usual" (UU) cholinesterase activity, in order to study the performance of the evaluated method in the detection of quantitative defects of the enzyme. Finally, 300 genotypically normal subjects (UU) served as a control group (150 women and 150 men, age range 20 to 65 years).

Blood was taken from an antecubital vein and allowed to clot; after centrifugation, the unhaemolysed serum was separated from the cells and stored at $-20^{\circ} \mathrm{C}$ until required. Under such conditions of storage, cholinesterase activity has been shown to be constant for several years $(1,12)$.

\section{Measurement of enzyme catalytic activity}

Pseudocholinesterase catalytic concentration was expressed as $\mathrm{U}\left(\mu \mathrm{mol} \cdot \mathrm{min}^{-1}\right)$. All the enzymatic determinations were carried out in duplicate on a Cobas Bio analyser ( $F$. Hoffman La Roche and Co., Ltd., Basle, Switzerland) and the mean value was calculated. The precision of this analyser is $\pm 0.001 \mathrm{~A}$ at $410 \mathrm{~nm}$.

\section{Benzoylcholine as substrate}

Pseudocholinesterase assay using benzoylcholine as substrate was performed according to Panteghini \& Bonora (13). In particular, for dibucaine inhibition, a concentration of $350 \mu \mathrm{mol} / 1$ of the inhibitor was used (13).

\section{Succinyldithiocholine as substrate}

The "Atypical Cholinesterase" assay was a gift from Sclavo S. p. A., Siena, Italy (kit product No. 81196). The assay is based on the method of Hersh et al. (8): the hydrolysis of succinyldithiocholine is assayed by reacting the liberated thiol with $5,5^{\prime}-$ dithio-bis-(2-nitrobenzoic acid), analogous to the procedure of Ellman et al. (15). More than $90 \%$ of the choline released is derived from the first step of succinyldithiocholine hydrolysis; the next step, conversion of succinylmonothiocholine to succinic acid, proceeds very slowly (16). The enzymatic activity was calculated using $1360 \mathrm{~m}^{2} \cdot \mathrm{mol}^{-1}$ as the molar lineic absorbance value for 5-thio-2-nitrobenzoic acid, the product of the reaction (13).

\section{Reagents}

The kit, not commercially available at the time of writing, consists of separate reagents for "Chromogen" and "Substrate". The optimal concentrations for reagent solutions had been determined in previous titration experiments (Tabacco, data not published).

\section{Chromogen}

5,5'-Dithio-bis-(2-nitrobenzoic acid) $0.8 \mathrm{mmol} / 1$ in $50 \mathrm{mmol} / 1$ phosphate buffer, $\mathrm{pH} 7.2$, containing $0.6 \mathrm{~g}$ of Lialet detergent per liter. This is stable for at least one year if kept refrigerated in a dark bottle.

\section{Substrate}

Succinyldithiocholine iodide, $5 \mathrm{mmol} / \mathrm{l}$ in solvent (dimethyl sulphoxide and ethanol, $75+25$ by vol.). This solution was diluted $1: 10$ with Chromogen reagent for use. The working solution is stable for up to ten days when stored at $4{ }^{\circ} \mathrm{C}$.

\section{Procedure}

The Cobas Bio was operated according to the setting shown in table 1 , unless otherwise stated.

Tab. 1. Parameter listing for determination of pseudocholinesterase catalytic activity on the Cobas Bio by the proposed method.

\begin{tabular}{lc}
\hline Reaction & + \\
Units & $\mathrm{U} / 1$ \\
Calculation factor & 613 \\
Standard concentration & 0 \\
Limit & 0.25 \\
Temperature & $37^{\circ} \mathrm{C}$ \\
Type of analysis & 3 (reaction rate) \\
Wavelength & $410 \mathrm{~nm}$ \\
Sample volume & $30 \mu \mathrm{l}$ \\
Diluent volume & $30 \mu \mathrm{l}$ \\
Reagent volume & $180 \mu \mathrm{l}$ \\
Incubation time & $120 \mathrm{~s}$ \\
Start reagent (substrate) volume & $20 \mu \mathrm{l}$ \\
Time of first reading & $90 \mathrm{~s}$ \\
Time interval & $10 \mathrm{~s}$ \\
Number of readings & 21 \\
Blanking mode & 1 (reagent blank) \\
\hline
\end{tabular}

\section{Results}

Determination of pseudocholinesterase catalytic activity

The spontaneous hydrolysis of succinyldithiocholine was minimal $(\Delta \mathrm{A} / \mathrm{min}<0.001)$ with the reagent conditions used in the test.

A calibration curve relating serum volume to the hydrolysis of succinyldithiocholine was prepared, using serum with an activity of $54 \mathrm{U} / 1$. The hydrolysis rate of succinyldithiocholine was linearly related to the volume of serum up to $30 \mu \mathrm{l}$ (fig; 1 ). 


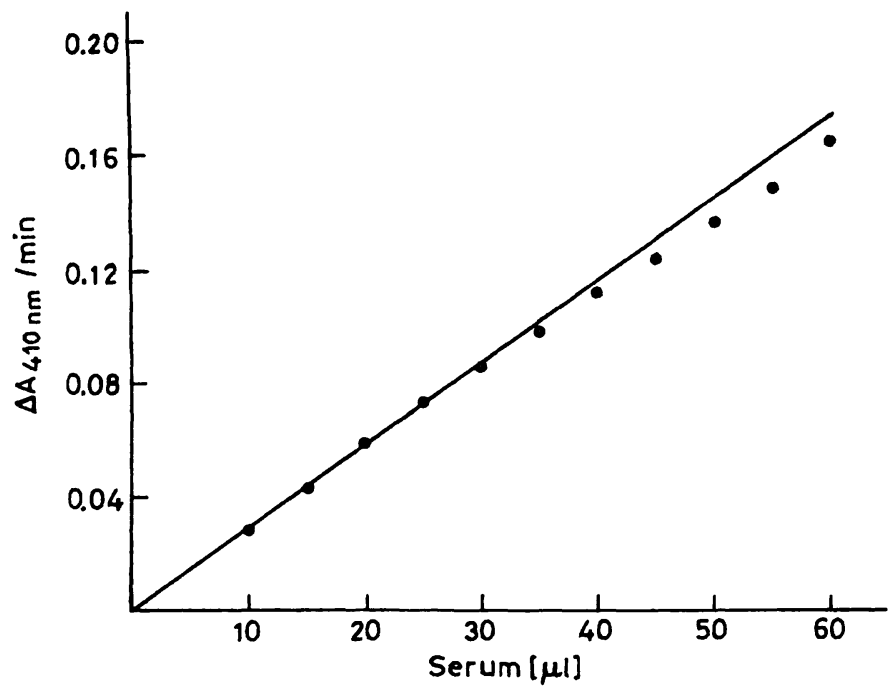

Fig. 1. Effect of amount of serum used in the assay system on the measured pseudocholinesterase catalytic activity.

The incubation time of $120 \mathrm{~s}$ assures the conclusion of the nonspecific reaction between the sulphydryl groups of serum and 5,5'-dithio-bis-(2-nitrobenzoic acid) before the start of the enzyme activity determination. Investigation of the effect of the lag time on the linearity of the enzymatic reaction showed that the best linearity is obtained with a lag phase of at least $90 \mathrm{~s}$ (tab. 2).

Tab. 2. Effect of lag time on the linearity of the enzymatic reaction.

\begin{tabular}{lc}
\hline Lag time, s & $\begin{array}{l}\text { No. of linear readings vs } \\
\text { total readings, \% }\end{array}$ \\
\hline 30 & 67 \\
45 & 70 \\
60 & 77 \\
75 & 85 \\
90 & 95 \\
105 & 100 \\
\hline
\end{tabular}

\section{Linearity}

Under the described standard assay conditions, the reaction is linear up to $90 \mathrm{U} / 1$ of serum pseudocholinesterase $(\Delta \mathrm{A} / \mathrm{min}=0.147)$. Serum with an activity of $88 \mathrm{U} / 1$ was serially diluted in saline; for this specimen, the theoretical results were $88,44,22,11,5.5$, 3 , and $1.5 \mathrm{U} / \mathrm{l}$; the corresponding experimental absorbance values per min were respectively 0.144 , $0.077,0.042,0.020,0.009,0.005$, and 0.002 . This response is highly linear $(r=0.9987$; standard error of estimation, 0.0089 ).

\section{Precision}

Precision studies using human sera with low, normal, and above-normal catalytic concentrations of pseudo- cholinesterase are shown in table 3 . The coefficient of variation in serial analyses is between 0.9 and $2.8 \%$; between-day analysis of 10 observations for five different serum samples gives coefficients of variation between 1.1 and $3.7 \%$.

Tab. 3. Precision of pseudocholinesterase determination by the evaluated method.

\begin{tabular}{|c|c|c|c|c|c|}
\hline \multicolumn{3}{|c|}{ Within-run $(n=20)$} & \multicolumn{3}{|c|}{ Between-day $(\mathbf{n}=10)$} \\
\hline $\begin{array}{l}\text { Mean, } \\
\text { U/1 }\end{array}$ & $\begin{array}{l}\mathrm{SD}, \\
\mathrm{U} / 1\end{array}$ & $\begin{array}{l}C V, \\
\%\end{array}$ & $\begin{array}{l}\text { Mean, } \\
\text { U/l }\end{array}$ & $\begin{array}{l}\mathrm{SD}, \\
\mathrm{U} / \mathrm{l}\end{array}$ & $\begin{array}{l}\mathrm{CV}, \\
\%\end{array}$ \\
\hline 1.8 & 0.05 & 2.8 & 1.9 & 0.07 & 3.7 \\
\hline 17.6 & 0.26 & 1.5 & 17.7 & 0.44 & 2.5 \\
\hline 30.3 & 0.36 & 1.2 & 30.0 & 0.42 & 1.4 \\
\hline 48.3 & 0.43 & 0.9 & 49.0 & 0.64 & 1.3 \\
\hline 87.2 & 0.87 & 1.0 & 86.9 & 0.96 & 1.1 \\
\hline
\end{tabular}

\section{Interference studies}

The addition of various kinds of anticoagulant, such as ethylenediaminetetraacetic acid dipotassium salt $(2.5 \mathrm{mmol} / \mathrm{l})$, sodium citrate $(20 \mathrm{mmol} / \mathrm{l})$ or lithium heparin $(1 \mathrm{~g} / 1)$ had no effect on pseudocholinesterase activity in the method being evaluated. On the other hand, sodium fluoride, a known inhibitor of pseudocholinesterase (6), at a concentration of $50 \mathrm{mmol} / \mathrm{l}$, reduces cholinesterase activity by $50 \%$. Reducing substances, i.e. ascorbic acid, glucose, creatinine, and uric acid do not interfere at concentrations up to 140 $\mu \mathrm{mol} / \mathrm{l}, 55 \mathrm{mmol} / \mathrm{l}, 4500 \mu \mathrm{mol} / \mathrm{l}$, and $2000 \mu \mathrm{mol} / \mathrm{l}$, respectively. Again, albumin up to $150 \mathrm{~g} / \mathrm{l}$ does not interfere with the evaluated method. Table 4 shows the interference studies on pseudocholinesterase determination for increasing concentrations of haemoglobin, triacylglycerols, and bilirubin. Finally, succinyldithiocholine is not hydrolysed by human red-cell cholinesterase (EC 3.1.1.7).

\section{Reference interval}

After conditions for the method were established, the procedure was applied to the determination of serum pseudocholinesterase catalytic activity in apparently healthy subjects. Employing nonparametric determination of percentiles (17), we determined the reference limits of pseudocholinesterase activity in 300 individuals with normal serum biochemical and haematological tests (dibucaine number $>75$ ) and without clinical evidence of diseases or conditions that might depress or increase cholinesterase activity. The reference interval was estimated to be $34-77 \mathrm{U} / 1(95 \%$ central range). The reference limits for males ( $40-78$ $\mathrm{U} / \mathrm{l})$ were significantly higher than those for females (33-76U/1) $(p<0.01)$, in accordance with other studies $(13,14,18,19)$. 
Tab. 4. Inferference studies on pseudocholinesterase catalytic activity determination with the evaluated method.

\begin{tabular}{|c|c|c|}
\hline $\begin{array}{l}\text { Original serum } \\
U / 1\end{array}$ & $\begin{array}{l}\text { Observed activity } \\
\text { U/1 }\end{array}$ & \\
\hline & & $\begin{array}{l}\text { Haemoglobin } \\
\mathrm{g} / \mathrm{l}\end{array}$ \\
\hline \multirow[t]{2}{*}{49} & $\begin{array}{l}50 \\
49 \\
49 \\
\left.27^{*}\right) \\
\left.3^{*}\right)\end{array}$ & $\begin{array}{l}0.25 \\
0.50 \\
1.00 \\
2.00 \\
4.00\end{array}$ \\
\hline & & $\begin{array}{l}\text { Triacylglycerols } \\
\mathrm{mmol} / \mathrm{l}\end{array}$ \\
\hline \multirow[t]{2}{*}{50} & $\begin{array}{l}50 \\
49 \\
\left.44^{*}\right) \\
\left.36^{*}\right)\end{array}$ & $\begin{array}{r}4 \\
6 \\
8 \\
16\end{array}$ \\
\hline & & $\begin{array}{l}\text { Bilirubin } \\
\mu \mathrm{mol} / 1\end{array}$ \\
\hline 32 & $\begin{array}{l}32 \\
32 \\
31 \\
31 \\
\left.29^{*}\right) \\
\left.25^{*}\right)\end{array}$ & $\begin{array}{r}65 \\
90 \\
128 \\
170 \\
265 \\
342\end{array}$ \\
\hline
\end{tabular}

*) Significantly different value from original serum at $\mathrm{p}<0.01$.

Comparison studies in pathological conditions

238 patients were investigated during the course of this work:

a) 14 were homozygous for the "atypical" enzyme;

b) 195 were "heterozygous" for the usual and the atypical gene;

c) 29 had "usual" enzyme and associated severe impairment of hepato-cellular function (hepatic cirrhosis in terminal stage).

Results for pseudocholinesterase catalytic activities and dibucaine numbers for the three groups compared with the reference group (see above) are shown in table 5. Comparison between pseudocholinesterase catalytic activity, obtained with the present method, and dibucaine number is also presented in figure 2. The median value of the homozygous AA patients was $1.5 \mathrm{U} / 1$ with a maximum value of $4 \mathrm{U} / \mathrm{l}$. The "heterozygous" UA patients were included within the range 5-35 U/1. Analysis of this group shows a large excess of female over male patients mainly in the subgroup with cholinesterase values between 5 and $15 \mathrm{U} / \mathrm{l}$ (fig. 3). In particular, about $50 \%$ of the subjects of this subgroup were pregnant women. Of the 29 cirrhotic patients, 28 fell within the range $6-15 \mathrm{U} / 1$. The 29th case, having a value of $4 \mathrm{U} / \mathrm{l}$., was, however, exceptional (pseudocholinesterase activity with benzoylcholine as substrate was only $185 \mathrm{U} / 1$, namely about $9 \%$ of median reference value).

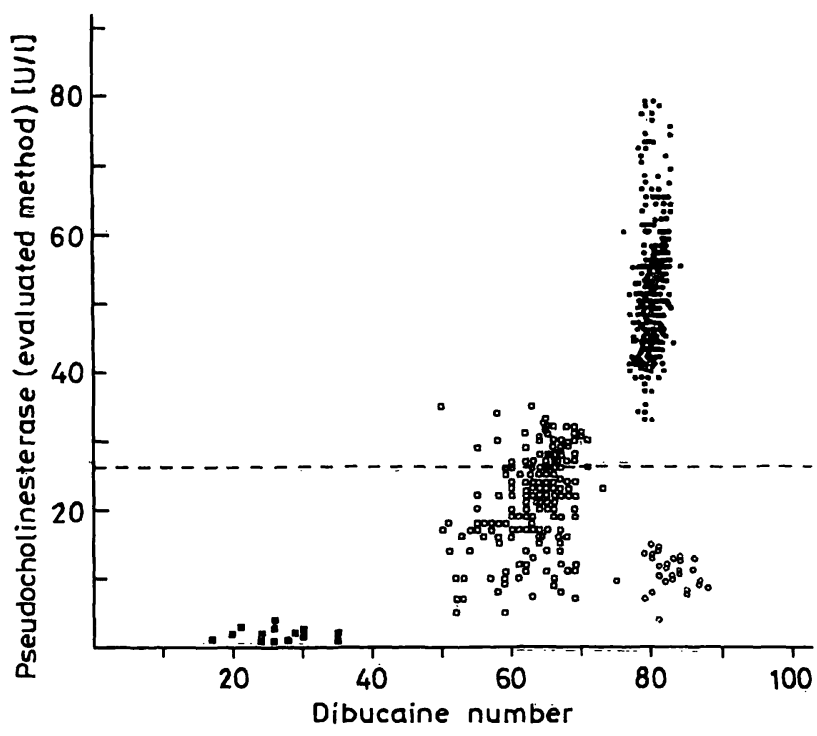

Fig. 2. Correlation between serum pseudocholinesterase catalytic activity obtained with the evaluated procedure ( $y$ axis) and dibucaine number ( $x$-axis).

Solid circle: "usual" enzyme $(n=300)$;

open square: "heterozygous" enzyme $(n=195)$;

solid square: "atypical" enzyme $(n=14)$;

open circle: "usual" enzyme and liver cirrhosis $(n=29)$. The dashed line indicates 2.5 SD below the mean activity for "usual" enzyme.

Tab. 5. Serum pseudocholinesterase catalytic concentration and dibucaine numbers (median values and ranges) in the groups of studied patients.

\begin{tabular}{|c|c|c|c|c|}
\hline Patients & $\begin{array}{l}\text { No. } \\
\text { of cases }\end{array}$ & $\begin{array}{l}\text { Pseudocholinesterase } \\
\text { catalytic concentration, U/1 } \\
\text { (benzoylcholine)*) }^{*}\end{array}$ & $\begin{array}{l}\text { Dibucaine number, } \\
\%^{*} \text { ) }\end{array}$ & $\begin{array}{l}\text { Pseudocholinesterase } \\
\text { catalytic concentration, U/1 } \\
\text { (succinyldithiocholine)**) }\end{array}$ \\
\hline $\begin{array}{l}\text { UU genotype } \\
\text { UA genotype } \\
\text { AA genotype } \\
\text { UU genotype + } \\
\text { liver cirrhosis }\end{array}$ & $\begin{array}{r}300 \\
195 \\
14 \\
29\end{array}$ & $\begin{array}{r}2117(1754-3883) \\
1340(445-1920) \\
625(370-1480) \\
503(185-680)\end{array}$ & $\begin{array}{l}80(76-84) \\
64(50-73) \\
26(17-35) \\
82(75-88)\end{array}$ & $\begin{array}{cr}51 & (33-79) \\
22 & (5-35) \\
1.5 & (1-4) \\
11 & (4-15)\end{array}$ \\
\hline
\end{tabular}




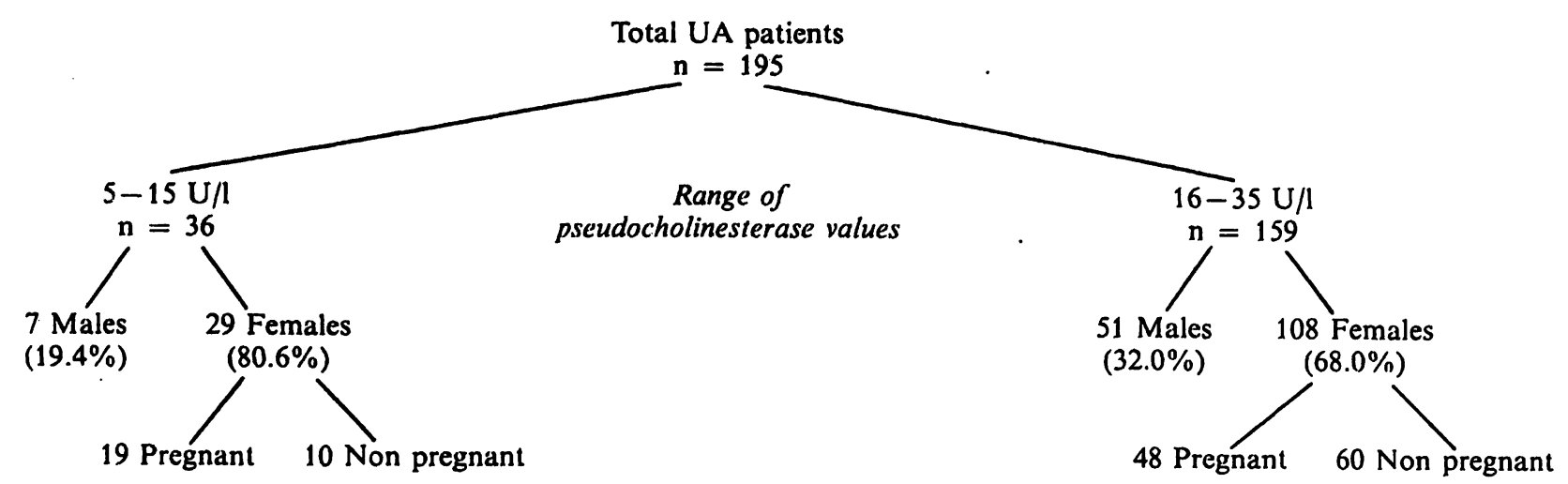

Fig. 3. Analysis of the genotype UA patients included in this study.

The optimum dividing line between the pseudocholinesterase activities of sensitive and nonsensitive individuals has been recommended by Dietz et al. (12) as 2.5 SD below the mean activity for genotypically normal subjects. For the present method the corresponding cut-off value is $26 \mathrm{U} / 1$ (fig. 2). This finding compares favorably with that recently reported by Faye \& Evans, who used succinyldicholine as substrate (20).

\section{Discussion}

The proposed method was developed in an attempt to improve the prediction of succinyldicholine sensitivity by direct measurement of the in vitro rate of succinyldithiocholine hydrolysis. This assumption is substantiated by the work of Hersh et al. (8) who showed that succinyldithiocholine, as an analogue of succinyldicholine, is a substrate for pseudocholinesterase. Thus, the ability to hydrolyse succinyldithiocholine itself should be the criterion in detecting succinyldicholine-sensitive individuals and should overcome the problems of extrapolating from studies with other nonpharmacological substrates with and without inhibitor $(4,7)$. In agreement with the recommendations of Dietz et al. (12), values of $<26 \mathrm{U} / 1$ could be tentatively regarded as suggesting succinyldicholine sensitivity. Any individual with a pseudocholinesterase catalytic activity below this critical level would be sensitive to succinyldicholine, regardless of genotype.

The present method results in extremely low activities with the "atypical" genotype $(<4 \mathrm{U} / 1)$, thereby permitting a clear differentiation between the homozygous and other groups of patients studied. Furthermore, unlike the methods with nonpharmacological substrates, a direct relationship was found between serum cholinesterase activity and the pathological response to succinyldicholine among the homozygous patients.
Cholinesterase activities of the "heterozygous" UA subjects indicate that several patients with this genotype can be sensitive to succinyldicholine. In particular, 135 patients $(69 \%)$ with genotype UA have cholinesterase activity $<26 \mathrm{U} / \mathrm{l}$. This percentage is remarkably higher than those found by Dietz et al. $(20 \%)$ using propionylthiocholine as substrate (12). However, Viby Mogensen (21) found that almost 50\% of patients with this genotype experience a moderately prolonged reaction to succinyldicholine. Therefore, succinyldithiocholine appears to be a more sensitive indicator substrate of succinyldicholine sensitivity than is propionylthiocholine. The clinical implication of these findings is evident; mainly if the cholinesterase activity is reduced for environmental reasons, e. g., because of a concomitant pregnancy, a clinically significant prolonged paralysis may result in UA subjects. In Whittaker's opinion (1) the UA "heterozygous" pregnant women having $50 \%$ or less of the average normal activity will probably be sensitive to succinyldicholine. In our study about $50 \%$ of the subjects of the "heterozygous" subgroup with lower cholinesterase activities $(<15 \mathrm{U} / \mathrm{l})$ were pregnant women. Thus, a higher proportion of "heterozygous" women would be expected to show sensitivity to succinyldicholine during pregnancy than when nonpregnant.

There are acquired causes for low pseudocholinesterase catalytic activity (1); in such circumstance the action of the inhibitors is normal. Nevertheless, prolonged apnoea following succinyldicholine has been reported in these patients in spite of the normal genotype (1). Viby Mogensen (22) shows that in these subjects the duration of succinyldicholine action increases with decreasing serum pseudocholinesterase activity. Also with the present method, it was possible to detect low enzyme activities in these subjects permitting a correlation of the level of pseudocholinesterase catalytic activity with the theoretical duration of apnoea following the administration of succinyldicholine. 
Recently some workers have used succinyldicholinebased procedures for assaying pseudocholinesterase $(20,23,24)$. However their methods are too cumbersome for routine use in the clinical laboratory, and sometimes the autohydrolysis of succinyldicholine makes difficult the determination of the lower pseudocholinesterase activities (23). With our test a large number of sera can be tested easily; therefore, the method is well suited for use in the routine clinical chemistry laboratory. Unlike the assay proposed by Abernethy et al. (23) which utilizes a single-point measurement, this system continually monitors the change in absorbance, thus alleviating the necessity for precise timing. Even trace amounts of succinyldithiocholine hydrolysis can be detected with high sensitivity. In particular, the use of an automatic analyser allows the measurement of the enzyme activity at levels of $1 \mathrm{U} / \mathrm{l}$. Finally, the reagents required are commercially available and the procedure appears to be applicable to several different types of automatic analysers.

\section{References}

1. Whittaker, M. (1980) Anaesthesia 35, 174-197.

2. Kalow, W. \& Genest, K. (1957) Can. J. Biochem. Physiol. $35,339-346$.

3. Garry, P. J. (1971) Clin. Chem. 17, 183-191.

4. Evans, R. T. \& Wroe, J. (1978) Clin. Chem. 24, 17621766.

5. Viby Mogensen, J. (1983) Dan. Med. Bull. 30, 129-150.

6. Harris, H. \& Whittaker, M. (1961) Nature 191, 496-498.

7. Davies, R. O., Marton, A. V. \& Kalow, W. (1960) Can. J. Biochem. Physiol. 38, 545-551.

8. Hersh, L. B., Prithvi Raj, P. \& Ohlweiler, D. (1974) J. Pharmacol. Exp. Ther. 189, 544-549.

9. Goodyer, P. \& Mautner, H. G. (1967) Biochem. Pharmacol. $16,2044-2046$.

10. Garry, P. J. \& Routh, J. I. (1965) Clin. Chem. 11, 91-96.

11. Whittaker, M., Britten, J. J. \& Dawson, P. J. G. (1983) Clin. Chem. 29, 1746-1751.

12. Dietz, A. A., Rubinstein, H. M. \& Lubrano, T. (1973) Clin. Chem. 19, 1309-1313.

13. Panteghini, M. \& Bonora, R. (1984) J. Clin. Chem. Clin. Biochem. 22, 671-676.
The most important clinical result of this study is that when only the screening of a surgical population for succinyldicholine sensitivity is desired, the proposed method enables the preoperative identification of patients who will have an abnormal response to succinyldicholine, without the determination of genotype by the measurement of inhibitor numbers. Indeed genotyping specimens, certainly best done by existing methods $(2,12,13)$, is complementary to the detection of sensitive individuals by our method. In particular, if preanaesthesia screening is used, it would be wise to prohibit the use of suxamethonium if the cholinesterase activity is less than $26 \mathrm{U} / 1$, although, in agreement with Dietz et al. (12), there will be some patients with values below $26 \mathrm{U} / \mathrm{l}$ who could probably tolerate succinyldicholine well. Theoretically, our method may allow a direct estimate of apnoea time, and this should be confirmed by clinical trials with the use of a nerve stimulator.

\section{Acknowledgement}

We thank Dr. A. Tabacco (S̈clavo S. p. A., Siena, Italy) for the supply of Atypical Cholinesterase assay sets.

14. Panteghini, M., Bonora, R. \& Pagañi, F. (1986) Clin. Biochem. 19, 161 - 165 .

15. Ellman, G. L., Courtney, K. D., Andres, V. \& Featherstone, R. M. (1961) Biochem. Pharmacol. 7, 88 -95.

16. Goedde, H. W., Held, K. R. \& Atland, K. (1968) Mol. Pharmacol. 4, 274-287.

17. Strike, P. W. (1981) Medical laboratory statistics, pp. $51-65$, J. Wright \& Sons, Bristol.

18. Sidell, F. R. \& Kaminskis, A. (1975) Clin. Chem. 21, 1393 1395.

19. Lepage, L., Schiele, F., Gueguen, R. \& Siest, G. (1985) Clin. Chem. 31, 546-550.

20. Faye, S. \& Evans, R. T. (1986) Clin. Chem. 32, 14771480.

21. Viby Mogensen, J. (1981) Anesthesiology 55, 231-235.

22. Viby Mogensen, J. (1980) Anesthesiology 53, 517-520.

23. Abernethy, M. H., George, P. M. \& Melton, V. E. (1984) Clin. Chem. 30, 192-195.

24. Wakid, N. W., Tubbeh, R. \& Baraka, A. (1985) Anesthesiology $62,509-512$.

Dr. Mauro Panteghini

$1^{\circ}$ Laboratorio Analisi Chimico=Cliniche Spedali Civili

I-25100 Brescia 